07;09

\title{
Солнечные элементы на основе сложных оксидов
}

\author{
() С.С. Козлов ${ }^{1}$, Л.Л. Ларина ${ }^{1}$, А.Б. Никольская ${ }^{1}$, О.В. Альмяшева ${ }^{2}$, О.В. Проскурина ${ }^{3}$, \\ О.И. Шевалеевский ${ }^{1, \uparrow}$ \\ ${ }^{1}$ Институт биохимической физики им. Н.М. Эмануэля РАН, Москва, Россия \\ ${ }^{2}$ Санкт-Петербургский государственный электротехнический университет „ЛЭтИ“, Санкт-Петербург, Россия \\ ${ }^{3}$ Физико-технический институт им. А.Ф. Иофрфе РАН, Санкт-Петербург, Россия \\ `E-mail: shevale2006@yahoo.com
}

Поступило в Редакцию 3 декабря 2020 г.

В окончательной редакции 10 декабря 2020 г.

Принято к публикации 10 декабря 2020 г.

Представлены результаты разработки новых неорганических перовскитных солнечных элементов с фотоактивным слоем на основе ортоферрита висмута $\left(\mathrm{BiFeO}_{3}\right)$ со структурой перовскита и фотоэлектродом на основе оксида циркония $\left(\mathrm{ZrO}_{2}\right)$. Исследовано поведение оптических и фотовольтаических характеристик перовскитных солнечных элементов в условиях как стандартного (AM1.5G), так и изменяемого в пределах $20-1000 \mathrm{~W} / \mathrm{m}^{2}$ освещения. Показана высокая долговременная стабильность параметров полученных перовскитных солнечных элементов в воздушной атмосфере при повышенной влажности.

Ключевые слова: перовскит, солнечный элемент, ортоферрит висмута, оксид циркония, допирование.

DOI: 10.21883/PJTF.2021.06.50758.18643

В последние годы развитие работ, связанных с совершенствованием перовскитных солнечных элементов (ПСЭ), относится к доминирующим направлениям исследований в области солнечной фотовольтаики [1]. ПСЭ на основе органо-неорганических соединений со структурой перовскита демонстрируют в стандартных условиях освещения AM1.5G эффективность преобразования энергии, превышающую $26 \%$ [2], что сравнимо с эффективностью традиционных фотопреобразователей на основе кристаллического кремния. На данный момент основной проблемой, препятствующей широкому внедрению ПСЭ, является низкая стабильность используемого в ПСЭ фотоактивного органо-неорганического перовскитного материала вида $\mathrm{CH}_{3} \mathrm{NH}_{3} \mathrm{PbI}_{3}$ [3]. При контакте с воздушной атмосферой, влагой, при нагреве и ультрафиолетовом освещении в структуре $\mathrm{CH}_{3} \mathrm{NH}_{3} \mathrm{PbI}_{3}$ наблюдается значительная деструкция, приводящая к существенному снижению ее фотофизических характеристик [4]. Различные попытки улучшить стабильность ПСЭ на основе $\mathrm{CH}_{3} \mathrm{NH}_{3} \mathrm{PbI}_{3}$ [5] пока не привели к значимым результатам. Многообещающим подходом стало направление, связанное с поиском и использованием в качестве фотоактивного слоя новых видов стабильных перовскитных материалов на основе неорганических соединений [6]. К наиболее перспективным для этой цели следует отнести полупроводниковые материалы на основе сложных оксидов со структурой перовскита, преимуществом которых является отсутствие в структуре токсичных элементов и галогенидов, а также высокая стабильность структурных параметров, которые не подвержены влиянию таких внешних факторов, как состав атмосферы, температурные эффекты и освещение [7]. Было показано, что для конструирования фотопреобразователей могут быть успешно использованы полупро- водниковые перовскиты на основе таких оксидов, как $\mathrm{KNiO}_{3}$ и $\mathrm{BiFeO}_{3}[8,9]$.

В настоящей работе представлены результаты разработки новых видов неорганических ПСЭ (НПСЭ) с фотоактивными слоями на основе нелегированного и легированного титаном ортоферрита висмута $\mathrm{BiFeO}_{3}$ (BFO) и фотоэлектродом на основе оксида циркония $\left(\mathrm{ZrO}_{2}\right)$. Получены данные по фотовольтаическим характеристикам НПСЭ как при стандартном освещении $\mathrm{AM} 1.5 \mathrm{G}$, так и в условиях изменяемого в пределах $20-1000 \mathrm{~W} / \mathrm{m}^{2}$ освещения. Проведены исследования временно́й стабильности параметров приготовленных НПСЭ в условиях высокой влажности ( 70\%).

Наночастицы перовскитоподобного ортоферрита висмута, BFO, с размером частиц $\sim 20 \mathrm{~nm}$ были синтезированы путем разложения соосажденных гидроокислов согласно ранее описанной технологии $[10,11]$. Были получены как недопированные образы BFO, так и образцы, допированные 3 at.\% диоксида титана $\mathrm{BFO}(\mathrm{Ti})$. Фазовый состав синтезированных частиц определялся методом рентгеноструктурного анализа. Полученные дифрактограммы обоих видов образцов показали наличие рефлексов фазы $\mathrm{BiFeO}_{3}$ (PDF 14-181). Показано, что параметры элементарных ячеек образцов соответствуют литературным данным [12].

Конструирование перовскитных фотопреобразователей типа НПСЭ проводилось по аналогии с разработанной ранее схемой и подробно описано в наших работах $[13,14]$. Для изготовления фотоэлектродов были использованы наночастицы $\mathrm{ZrO}_{2}$, полученные дегидратацией совместно осажденных гидроксидов в гидротермальных условиях. Фотоэлектроды на основе наноструктурированного слоя $\mathrm{ZrO}_{2}$ толщиной около $200 \mathrm{~nm}$ были сформированы на стеклянных подложках 


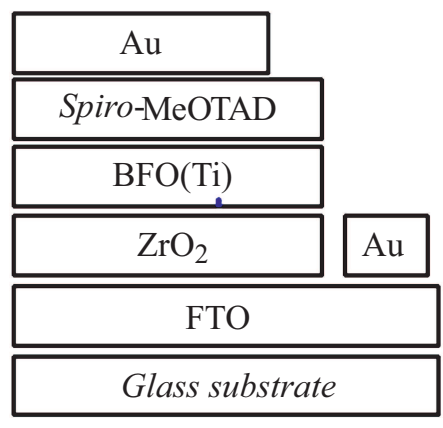

$a$

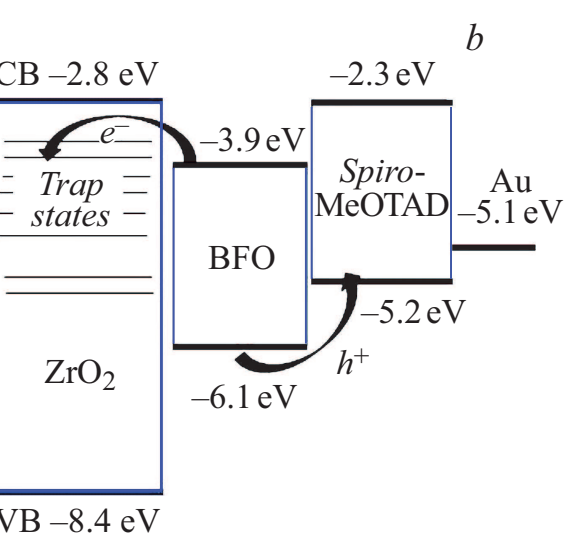

Рис. 1. Структурная схема (a) и энергетическая диаграмма $(b)$ НПСЭ на основе ортоферрита висмута.

с проводящим покрытием FTO (fluorine-doped tin oxide) методом спин-коутинга (spin-coating). Далее на поверхность фотоэлектрода последовательно наносились слои на основе наночастиц неорганического перовскита BFO или $\mathrm{BFO}(\mathrm{Ti})$ и дырочного проводника Spiro-MeOTAD $\left(\mathrm{C}_{81} \mathrm{H}_{68} \mathrm{~N}_{4} \mathrm{O}_{8}\right)$. Формирование НПСЭ завершалось нанесением токопроводящих золотых контактов толщиной около $50 \mathrm{~nm}$ методом напыления в вакууме. Все образцы готовились в условиях воздушной атмосферы при естественной влажности (40\%). В результате были приготовлены две серии фотопреобразователей типа НПСЭ со структурой стекло/FTO/ZrO $\left./ \mathrm{ZOF}_{2} / \mathrm{Ti}\right) / \mathrm{Spiro-}$ $\mathrm{MeOTAD/Au.} \mathrm{Для} \mathrm{первой} \mathrm{серии} \mathrm{НПСЭ} \mathrm{использова-}$ лись фотоактивные слои недопированного ВFO, для второй - слои допированного титаном $\mathrm{BFO}(\mathrm{Ti})$. На рис. 1,a представлена структурная схема сконструированных НПСЭ. Энергетическая структура НПСЭ и относительное расположение зон показано на рис. $1, b$. Особенностью конструкции приготовленных НПСЭ является использование в качестве фотоэлектродов наноструктурированных слоев на основе $\mathrm{ZrO}_{2}$ с очень широкой запрещенной зоной $(\sim 6 \mathrm{eV})$. Как было показано ранее, применение подобных электродов позволяет повысить эффективность традиционных ПСЭ за счет минимизации влияния рекомбинационных процессов на границе раздела перовскит-фотоэлектрод [15]. Следует отметить, что положение дна зоны проводимости фотоэлектрода $\mathrm{ZrO}_{2}$ располагается выше положения дна зоны проводимости фотоактивного перовскитного слоя ВFО. В такой энергетической конфигурации процесс переноса фотовозбужденных носителей заряда с фотоактивного слоя на фотоэлектрод может эффективно осуществляться на основе прыжкового механизма за счет высокой концентрации локализованных состояний в запрещенной зоне $\mathrm{ZrO}_{2}$ [15].

На рис. 2 представлены спектры оптического поглощения наноструктурированных слоев $\mathrm{BFO}$ и $\mathrm{BFO}(\mathrm{Ti})$ толщиной $\sim 300 \mathrm{~nm}$, которые были получены на специально приготовленных на стеклянных подложках образцах. Энергии запрещенной зоны $E_{g}$ для BFO и $\mathrm{BFO}(\mathrm{Ti})$ вычислялись на основании анализа спектральных зависимостей коэффициента поглощения графической экстраполяцией линейных участков зависимостей $(\alpha h v)^{2}$ от энергии фотона и составили соответственно 2.43 и $2.11 \mathrm{eV}$.

Измерение фотовольтаических характеристик НПСЭ проводилось как при стандартном освещении AM1.5G $\left(1000 \mathrm{~W} / \mathrm{m}^{2}\right)$, так в условиях изменения освещенности в диапазоне $10-1000 \mathrm{~W} / \mathrm{m}^{2}$ с использованием имитатора солнечного излучения Abet Technologies Solar Simulator (США) и специальных понижающих освещение фильтров. Наилучшее значение эффективности $(\eta)$ в условиях освещения AM1.5G было получено для НПСЭ на основе допированного образца $\mathrm{BFO}(\mathrm{Ti})$ и составило 2.4\%. Фотоэлектрические параметры для обоих типов исследованных НПСЭ приведены в таблице. Видно, что в сравнении с недопированным в допированном образце наблюдается рост коэффициента заполнения $(F F)$ на $29 \%$ и напряжения холостого хода $\left(V_{o c}\right)$ на $45 \%$. Значительное увеличение происходит в величине плотности тока короткого замыкания $\left(J_{s c}\right)$, что может быть объяснено улучшением морфологии перовскитного слоя вследствие допирования и его более высокой кристалличностью, что в конечном счете выражается в сниже-

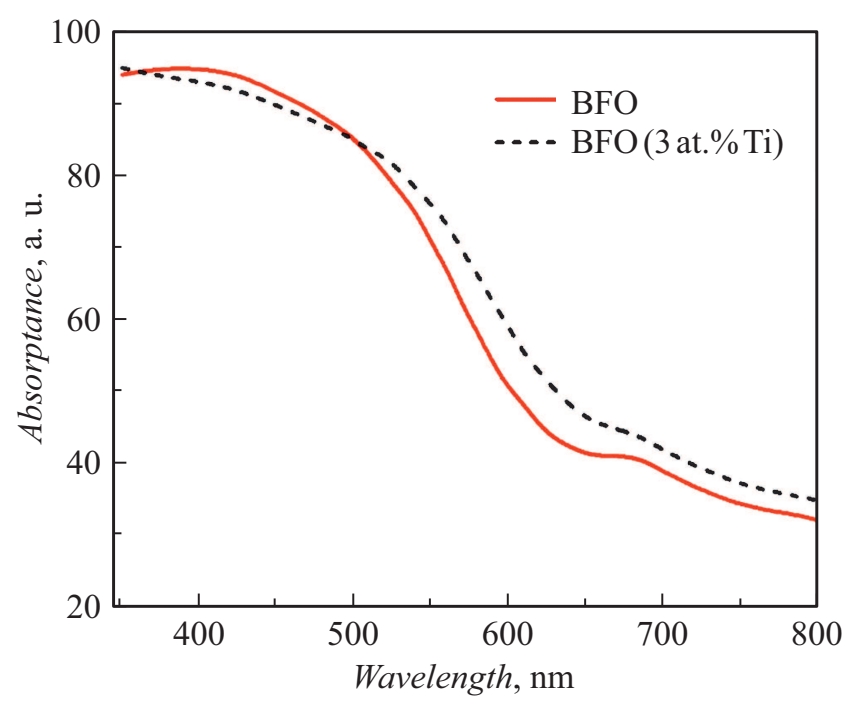

Рис. 2. Кривые оптического поглощения нелегированного и легированного титаном слоя ортоферрита висмута. 


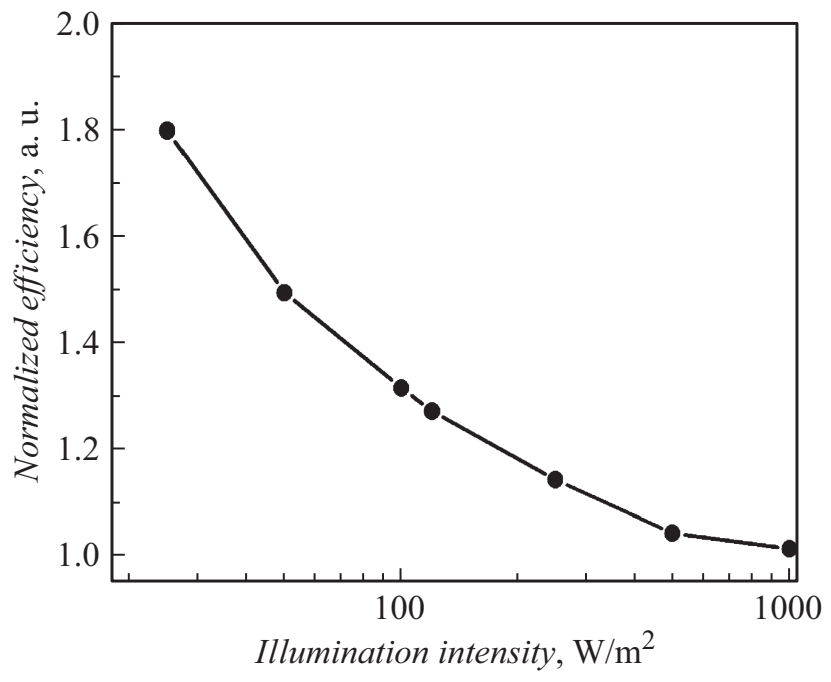

Рис. 3. Изменение эффективности НПСЭ на основе фотоактивного слоя $\mathrm{BFO}(\mathrm{Ti})$ в зависимости от интенсивности освещения.

Фотовольтаические параметры НПСЭ на основе ВFО

\begin{tabular}{c|c|c|c|c}
\hline Состав перовскита & $J_{s c}, \mathrm{~mA} / \mathrm{cm}^{2}$ & $V_{o c}, \mathrm{mV}$ & $F F, \%$ & $\eta, \%$ \\
\hline $\mathrm{BiFeO}_{3}$ & 0.42 & 510 & 45.3 & 0.1 \\
$\mathrm{BiFeO}_{3}$ (3 at.\% Ti) & 5.65 & 740 & 58.4 & 2.4
\end{tabular}

нии рекомбинационных потерь и улучшении фотоэлектрических параметров слоя $\mathrm{BFO}(\mathrm{Ti})$.

На рис. 3 представлен график изменения эффективности преобразования для образца НПСЭ на основе $\mathrm{BFO}(\mathrm{Ti})$ при изменении интенсивности освещения в диапазоне $20-1000 \mathrm{~W} / \mathrm{m}^{2}$. Показано, что по мере уменьшения освещенности образца эффективность преобразования растет и при низких значениях освещенности в 1.8 раза превышает начальное значение. Аналогичное поведение наблюдается и в традиционных ПСЭ на основе органо-неорганических систем [16].

В НПСЭ на основе $\mathrm{BFO}(\mathrm{Ti})$ было проведено исследование временно́й стабильности фотовольтаических параметров в естественной воздушной атмосфере в условиях повышенной влажности $(\sim 70 \%)$ в течение 30 дней. Установлено, что основные характеристики, включая эффективность, претерпели незначительное снижение, не превышающее нескольких процентов. Некоторое уменьшение значения коэффициента заполнения $F F$ (с 58.4 до $57.1 \%)$, с нашей точки зрения, связано с возможными изменениями на границах раздела слоев $\mathrm{ZrO}_{2} / \mathrm{BFO}(\mathrm{Ti})$ и $\mathrm{BFO}(\mathrm{Ti}) /$ Spiro-MeOTAD. При этом сравнительный анализ структурных характеристик фотоактивного слоя $\mathrm{BFO}(\mathrm{Ti})$, проведенный методом рентгенофазового анализа до и после 30-дневного пребывания образцов в условиях повышенной влажности, не выявил значимых изменений, что указывает на отсутствие деградацион- ных процессов в структуре перовскитного материала $\mathrm{BFO}(\mathrm{Ti})$.

Таким образом, нами были приготовлены наноструктурированные слои на основе перовскитоподобного недопированного и допированного титаном ортоферрита висмута, BFO и $\mathrm{BFO}(\mathrm{Ti})$, и исследованы их структурные и оптические характеристики. На их основе впервые разработаны и изучены НПСЭ со структурой стекло/FTO $/ \mathrm{ZrO}_{2} / \mathrm{BFO}(\mathrm{Ti}) /$ Spiro-MeOTAD/Au. Наилучшая эффективность, которая составила в условиях стандартного освещения AM1.5G величину $2.4 \%$, была получена для НПСЭ на основе фотоактивного слоя $\mathrm{BFO}(\mathrm{Ti})$. Установлено, что при длительной экспозиции в условиях высокой влажности структурные параметры фотоактивного слоя $\mathrm{BFO}(\mathrm{Ti})$ и фотовольтаические характеристики НПСЭ на его основе практически не изменяются. Показано также, что по мере уменьшения интенсивности освещения эффективность разработанных НПСЭ значительно возрастает.

\section{Финансирование работы}

Исследование выполнено за счет гранта Российского научного фонда (проект № 20-69-47124).

\section{Конфликт интересов}

Авторы заявляют, что у них нет конфликта интересов.

\section{Список литературы}

[1] N.-G. Park, Adv. Energy Mater., 10 (13), 1903106 (2019). DOI: $10.1002 /$ aenm.201903106

[2] A. Rohatgi, K. Zhu, J. Tong, D. Kim, E. Reichmanis, B. Rounsaville, V. Prakash, Y.-W. Ok, IEEE J. Potovolt., 10 (2), 417 (2020). DOI: 10.1109/JPHOTOV.2019.2963564

[3] J. Schoonman, Chem. Phys. Lett., 619, 193 (2015). DOI: $10.1016 /$ j.cplett.2014.11.063

[4] Z. Song, S.C. Watthage, A.B. Phillips, M.J. Heben, J. Photon. Energy, 6 (2), 022001 (2016). DOI: 10.1117/1.JPE.6.022001

[5] M. Saliba, T. Matsui, J.-Y. Seo, K. Domanski, J.-P. CorreaBaena, M.K. Nazeeruddin, S.M. Zakeeruddin, W. Tress, A. Abate, A. Hagfeldt, M. Gratzel, Energy Environ. Sci., 9 (6), 1989 (2016). DOI: 10.1039/C5EE03874J

[6] M.S. Sheikh, D. Ghosh, A. Dutta, S. Bhattacharyya, T.P. Sinha, Mater. Sci. Eng. B, 226, 10 (2017). DOI: $10.1016 /$ j.mseb.2017.08.027

[7] K. Kumari, T. Chakrabarti, A. Jana, D. Bhattachartjee, B. Gupta, S.K. Sarkar, Opt. Mater., 84, 681 (2018). DOI: 10.1016/j.optmat.2018.07.071

[8] T. Choi, S. Lee, Y. Choi, V. Kiryukhin, S.W. Cheong, Science, 324, 63 (2009). DOI: 10.1126/science. 1168636

[9] S.Y. Yang, L.W. Martin, S.J. Byrnes, T.E. Conry, S.R. Basu, D. Paran, L. Reichertz, J. Ihlefeld, C. Adamo, A. Melville, Y.H. Chu, C.H. Yang, J.L. Musfeldt, D.G. Schlom, J.W. Ager, R. Ramesh, Appl. Phys. Lett., 95 (6), 062909 (2009). DOI: $10.1063 / 1.3204695$ 
[10] О.В. Проскурина, И.В. Ноговицин, Т.С. Ильина, Д.П. Данилович, Р.Ш. Абиев, В.В. Гусаров, ЖОХ, 88 (10), 1699 (2018). [Пер. версия: 10.1134/S1070363218100183].

[11] O.V. Proskurina, R.S. Abiev, D.P. Danilovich, V.V. Panchuk, V.G. Semenov, V.N. Nevedomsky, V.V. Gusarov, Chem. Eng. Process. - Process Intensif., 143, 107598 (2019).

DOI: $10.1016 /$ j.cep.2019.107598

[12] М.И. Морозов, Н.А. Ломанова, В.В. Гусаров, ЖОХ, 73 (11), 1772 (2003).

[Пер. версия: 10.1023/B:RUGC.0000018640.30953.70].

[13] О.И. Шевалеевский, А.Б. Никольская, М.Ф. Вильданова, С.С. Козлов, О.В. Алексеева, А.А. Вишнёв, Л.Л. Ларина, Хим. физика, 37 (8), 36 (2018). DOI: $10.1134 / \mathrm{S} 0207401 \mathrm{X} 18080186$

[14] А.Б. Никольская, С.С. Козлов, М.Ф. Вильданова, О.И. Шевалеевский, ФТП, 53 (4), 550 (2019). DOI: 10.21883/FTP.2019.04.47456.9023

[15] M.F. Vildanova, S.S. Kozlov, A.B. Nikolskaia, O.I. Shevaleevskiy, N.A. Tsvetkov, O.V. Alexeeva, L.L. Larina, Nanosyst.: Phys. Chem. Math., 8 (4), 540 (2017). DOI: 10.17586/2220-8054-2017-8-4-540-545

[16] J. Lim, H. Kwon, J.W. Lim, H. Kwon, S.H. Kim, Y.J. You, J.S. Goo, D.H. Ko, H.J. Lee, D. Kim, I. Chung, T.G. Kim, D.H. Kim, J.W. Shim, Nano Energy, 75, 104984 (2020). DOI: 10.1016/j.nanoen.2020.104984 